\title{
The Performance of Hybrid Anaerobic Membrane Bioreactors (AnMBRs) Added with Powdered Activated Carbon (PAC) Based on Different Sludge Retention Times
}

\author{
E-Chuan Tan, Sze Pin Tan, Meng Khai Low, Po Kim Lo, Mohammed J.K. Bashir, \\ Andrew Chai Han Liang, Humaira Nisar and Choon Aun Ng*
}

\author{
Faculty of Engineering and Green Technology, University of Tunku Abdul Rahman, 31900 Kampar Perak \\ Malaysia
}

\begin{abstract}
In this study, the effects of different sludge retention times (SRTs) on membrane fouling control with the addition of powdered activated carbon (PAC) were investigated for the anaerobic membrane bioreactors (AnMBRs). Chemical oxygen demand (COD), mixed liquor volatile suspended solids (MLVSS), food to microorganisms (F/M) ratio, particle size distribution, extracellular polymeric substances (EPS) and their relationships with membrane fouling were studied for AnMBR added with PAC at different SRTs. As SRT of the AnMBR increased to higher days, MLVSS concentration would increase and F/M ratio decreased and it was found to have a better membrane fouling control. It was also noticed that PAC addition would decrease EPS concentration and increased the floc size of the biomass which would help to reduce membrane fouling rate of AnMBRs.
\end{abstract}

Keywords: Palm Oil Mill Effluent (POME), Anaerobic membrane bioreactor (AnMBR), membrane fouling, powdered activated carbon (PAC), sludge retention times (SRTs), F/M ratio.

\section{INTRODUCTION}

Malaysia is well known with its production of palm oil which accounts for $51 \%$ of world palm oil. Palm oil is one of the edible vegetable oil derived from the fleshy mesocarp of fruit of oil palm tree (species name: Elaeis Guinnesis). It was reported that Malaysia produces 14 million tons of palm oil from the oil palm tree that planted on 38,000 square kilometers of land. Approximately 11.9 million tons of crude palm oil (CPO) was produced with the amount of RM14.79 billion in year 2002. Despite of the recognized economical growth contribution, this industry may cause environmental pollution if its by-product is not properly treated. The water required to produce 1 ton of crude palm oil was estimated of 5-7.5 tons and more than $50 \%$ of water ends up as palm oil mill effluent (POME) [1]. The characteristics of POME are shown in Table 1 [2].

Current aerobic wastewater treatment plant requires large amount of energy, produces large amount of sludge, unable to recover valuable reusable resource in wastewater and therefore causing high cost of operation [3]. Anaerobic membrane bioreactor (AnMBR) is used to harvest energy, sustainable wastewater treatment alongside with reducing cost for operation. AnMBR is a combination of anaerobic

*Address correspondence to this author at the Faculty of Engineering and Green Technology, University of Tunku Abdul Rahman, 31900 Kampar Perak Malaysia; Tel: (60) 468 8888; Fax: (60) 466 7449; E-mail: ngca@utar.edu.my activated sludge and membrane filtration system in which allows wastewater treatment to be processed for cleaner effluent [4]. It is estimated that $12 \%$ increment of growth rate in MBR industry would occurred from year 2000 to 2013 [4]. AnMBRs have the similar benefits as aerobic membrane bioreactor (MBR) but they can be operated with the lower energy requirement [4]. Currently, membrane fouling is one of the major challenges to implement AnMBR treatment system due to its high operating and maintenance cost. In Table 2, the AnMBRs' performances were shown in terms of synthetic wastewater treatment removal rate in which to be evaluated for membrane fouling control. A recommended range of parameters for running a labscale AnMBR are shown in Table 3.

The main AnMBR operational conditions involve parameters such as $\mathrm{pH}$, SRT, temperature and hydrodynamic [5]. Anaerobic digestion is normally operates within the range of 6.5-8.5 with an optimum $\mathrm{pH}$ range of 7.0-8.0 and most of the AnMBR functions in the neutral $\mathrm{pH}$ condition [6]. It was reported that SRT and HRT could greatly influence the treatment efficiency. When SRT is increasing whilst HRT kept in constant, the suspended biomass was increasing and potentially leads to decrease in permeate flux $[7,8]$. Furthermore, increasing of SRT may result in higher soluble microbial production (SMP) and extracellular polysaccharide (EPS) production which accelerate membrane fouling rates with synthetic wastewater [8]. Huang et al. [8] also found out that the treatment performance is better at longer SRTs (comparing 
Table 1: Chemical Properties of Palm Oil Mill Effluent (POME)

\begin{tabular}{|c|c|c|c|}
\hline Property & Range & Property & Range \\
\hline \hline $\mathrm{pH}$ & $4.15-4.45$ & Total nitrogen & $300-410$ \\
\hline $\mathrm{BOD}$ & $21,500-24,500$ & Suspended solid & $15,660-23,560$ \\
\hline COD & $45,500-65,000$ & Total solid & $33,790-37,230$ \\
\hline Oil and grease & $1077-7582$ & Total volatile solids & $27,300-30,150$ \\
\hline
\end{tabular}

*Unit for all parameters is $\mathrm{mg} / \mathrm{L}$ except $\mathrm{pH}$.

Table 2: Comparison of AnMBR Performance in Synthetic Wastewater

\begin{tabular}{|c|c|c|c|c|}
\hline Types of wastewater & $\begin{array}{c}\text { Mixed-liquor Suspended Solids } \\
\text { (MLSS) (g/L) }\end{array}$ & COD removal (\%) & SRT & References \\
\hline \hline Sucrose-based & $11.45-16.12$ & 98 & $\sim 250$ & Akram and Stuckey, 2008 \\
\hline $\begin{array}{c}\text { Meat extract/ } \\
\text { Peptone-based }\end{array}$ & $2.5-3.9$ & 96 & 150 & Aquino, 2006 \\
\hline $\begin{array}{c}\text { Synthetic } \\
\text { sewage }\end{array}$ & - & 97 & 50 & Gao et al., 2010 \\
\hline $\begin{array}{c}\text { Synthetic simulating } \\
\text { municipal }\end{array}$ & $5-11.24$ & 95 & $-\infty$ & Huang et al., 2011 \\
\hline $\begin{array}{c}\text { Glucose-based } \\
\text { Synthetic simulating } \\
\text { municipal }\end{array}$ & $3.5-5.5$ & 95 & - & Hu and Stuckey, 2006 \\
\hline
\end{tabular}

operation SRTs of 30 and 60 days). However, studies $[9,10]$ reported that fouling rate of the membrane bioreactor with relatively higher SRT would decrease when extracellular polymeric substances (EPS) concentration in it decreased. They found that the higher SRT allowed microbial to be able to consume more substrates such as protein, carbohydrates and polysaccharides and less biopolymer would be produced. This relationship of SRT to treatment efficiency and membrane fouling are far more complex, and highly dependents on various parameters and feed characteristics [11]. AnMBR process prefers a relatively longer SRT to improve treatment performance, methane recovery rates and reduce in sludge

Table 3: Recommended Range for Operating Parameter and Condition for Lab Scale AnMBR

\begin{tabular}{|c|c|}
\hline Parameter & Lab scale AnMBR \\
\hline \hline Reactor capacity & $1-10 \mathrm{~L}$ \\
\hline Feed composition & Constant \\
\hline Hydraulic load & Constant \\
\hline Temperature & Constant room temperature \\
\hline Operating time & Hours-Months \\
\hline
\end{tabular}

Source: Kraume et al., 2009. production [11]. There are so many works done previously on different types of wastewater. Hence, this study is to investigate the treatment performance on POME which is rich in Malaysia.

Besides, the addition of powdered activated carbon (PAC) into the MBR would enhance microbial growth [12]. In addition, flux of membrane and COD removal efficiency had significant showed mark in which enhanced flux of the membrane and reduced membrane fouling as well as increase of removal rate by adding the PAC into MBR [13, 14]. Specific methanogenic activity (SMA) in AnMBR is found higher with addition of PAC compared to the AnMBR without PAC addition may be due to the relatively large supporting surface area provided by PAC which is used to protect the biomass from high shearing condition [15]. The adsorption capacity of PAC is enhanced not only by adsorption alone but also bio-regeneration of biological activated carbon (BAC) [12, 16]. The interaction action between PAC and microbial cell is synergistic and mutual. Enzyme is assumed to be secreted by the microbial cells deposited on or within PAC would eventually slip into the micropores [16].

There are only a few works reported on submerged AnMBR with addition of PAC especially about 
membrane fouling control at different SRTs. Therefore, this study is to investigate the treatment performance based on different SRTs added with PAC in AnMBR system.

\section{MATERIALS AND METHODS}

\subsection{Materials}

The powdered activated carbon (PAC) used in this study was pure charcoal originated from GENE Chem (Canada). Table 4 showed the specification of PAC used. A hollow fibre microfiltration Polyacrylonitrile membranes (nomical pore size: $0.5 \mu \mathrm{m}$ ) from Sakti Suria (JB) Sdn. Bhd. were used for filtration comparison. The seed of anaerobic activated sludge was taken from the local palm oil mill effluent (POME) treatment plant which is located in Gopeng, Perak, Malaysia.

Table 4: The Specification for the PAC Used in AnMBRs

\begin{tabular}{|c|c|}
\hline Composition & Value \\
\hline \hline $\mathrm{pH}$ & $4.5-7.5$ \\
\hline Soluble matter in ethanol & $0.20 \%$ \\
\hline Soluble matter in hydrochloric acid & $0.20 \%$ \\
\hline Chloride $(\mathrm{Cl})$ & $0.10 \%$ \\
\hline Sulfur compound $\left(\mathrm{SO}_{4}\right)$ & $0.15 \%$ \\
\hline Iron $(\mathrm{Fe})$ & $0.10 \%$ \\
\hline Zinc $(\mathrm{Zn})$ & $0.10 \%$ \\
\hline Heavy metal $(\mathrm{Pb})$ & $0.01 \%$ \\
\hline
\end{tabular}

\subsection{Operation of MBRs}

Five submerged anaerobic membrane bioreactors (AnMBRs) with the volume of $4.75 \mathrm{~L}$ were built. The first step to start up the bioreactor was to acclimatize the anaerobic sludge inoculum from the local palm oil mill plant to ensure the stabilization of bioactivity in the reactors. Different SRTs were used for each bioreactor namely as AnMBR (SRT 10 days without PAC), AnMBR (SRT 10 days added with PAC), AnMBR (SRT 30 days added with PAC), AnMBR (SRT 50 days added with PAC) and AnMBR (SRT 90 days added with PAC), respectively. $3.0 \mathrm{~g} / \mathrm{L}$ of PAC was added into four out of five ANMBRs with daily replenishment of fresh PAC. The AnMBRs were under the ambient temperature of $29^{\circ} \mathrm{C}$ and their HRT was set at 4 days.

\subsection{Analytical Methods}

Bound EPS and soluble EPS (SMP) are extensively known as the main foulants in the MBR system. They are characterized by its polysaccharide and protein contents. The concentration of protein was determined based on the Bradford reagent with bovine serum albumin (BSA) standard while the polysaccharide concentration was determined by using the phenolsulfuric acid method [17].

Particle size distribution of biomass flocs in AnMBRs were measured by using the Malvern Mastersizer 2000, Hydro2000 MU (A). The pH of the bioreactors was recorded from time to time by using a $\mathrm{pH}$ electrode meter (Hanna HI 2550).

Membrane fouling was measured using transmembrane pressure transducers, digital pressure data logger (Logit, USA). Method for the measurement of COD of the feedstock wastewater (initial influent) and final effluent were based on $\mathrm{HACH}$ method stated in Standard Method, $21^{\text {st }}$ Edition. Soluble COD was measured by centrifuging the mixed liquor samples. Subsequently, the filtrated samples were then further measured by using $\mathrm{HACH}$ test kit ranging from $0-1500$ $\mathrm{mg} / \mathrm{L}$. The mixed samples were then refluxed in a $\mathrm{HACH}$ COD digital reactor block (HACH-DRB 200) at $150{ }^{\circ} \mathrm{C}$ for 2 hours. After samples were cooled down, it was then analyzed using $\mathrm{HACH}$ UV/VIS spectrophotometer (Model DR 6000).

The determination of total suspended solid (TSS) and volatile suspended solid (VSS) were conducted by following Standard Method, $21^{\text {st }}$ Edition. The activated sludge samples were filtered through micro-glass fiber filter AH-934. The filter paper was then placed in an aluminum dish (Fisher Scientific, Pittsburg, PA, US) for weighing. To determine the TSS, the filter was first place into the oven for 2 hours with the temperature of 103-105 ${ }^{\circ} \mathrm{C}$. After that, the aluminum dish was transferred into a desiccator for cooling purpose before it was weighed. The measurement of VSS was carried out at $550^{\circ} \mathrm{C}$ in a furnace for 20 minutes. Lastly, it was transferred to a desiccator for cooling process before being weighed.

\section{RESULTS AND DISCUSSION}

\subsection{Effect of Different SRTs on Membrane Fouling Control of AnMBRs}

The short term filtration performance of the different AnMBRs with and without PAC at the different operating SRTs is shown in Figure 1. It was found that AnMBR with SRT of 10 days without addition of PAC showed the worst performance in membrane fouling control. TMP "jump" occurred after it was operated for 




Figure 1: Comparison of performance of membrane fouling control of the AnMBRs with different SRTs.

about 2 minutes. In this study, the other AnMBRs added with PAC showed a relatively better membrane fouling control. The AnMBRs with higher SRT and added with PAC had better result in which the AnMBR with the highest SRT (90 days) is the best performer.

PAC could be transformed to become biologically activated carbon (BAC) in the AnMBR. This transformation would increase the particle size distribution of the activated sludge flocs (Figure 2) in the AnMBR with PAC addition and led to better filtration performance as per Figure 1. PAC could also effectively enhance the microbial growth (Figure 3) which indicated that BAC could effectively help to biodegrade and reduce the chemical oxygen demand (COD) (Table 5) and total EPS (Figure 4) in the AnMBR and subsequently improved the AnMBRs added with PAC by having better membrane fouling control.

Membrane fouling control of the AnMBRs added with PAC was found could be improved with the higher SRT. This means the longer the SRT of the AnMBR, the better its' membrane fouling control. AnMBR added PAC operated at the 90 days of SRT has the best result in this study. This may be due to its higher substrate consumption rate under prolonged SRT that caused EPS and COD concentrations to decrease and the particle size of activated sludge flocs increased as per Figure 4, Table 5 and Figure 2 respectively. This indicates that the reduction of EPS and COD concentrations and increment of particle sizes of the biosmass flocs in the AnMBRs (added PAC) helped in membrane fouling control.

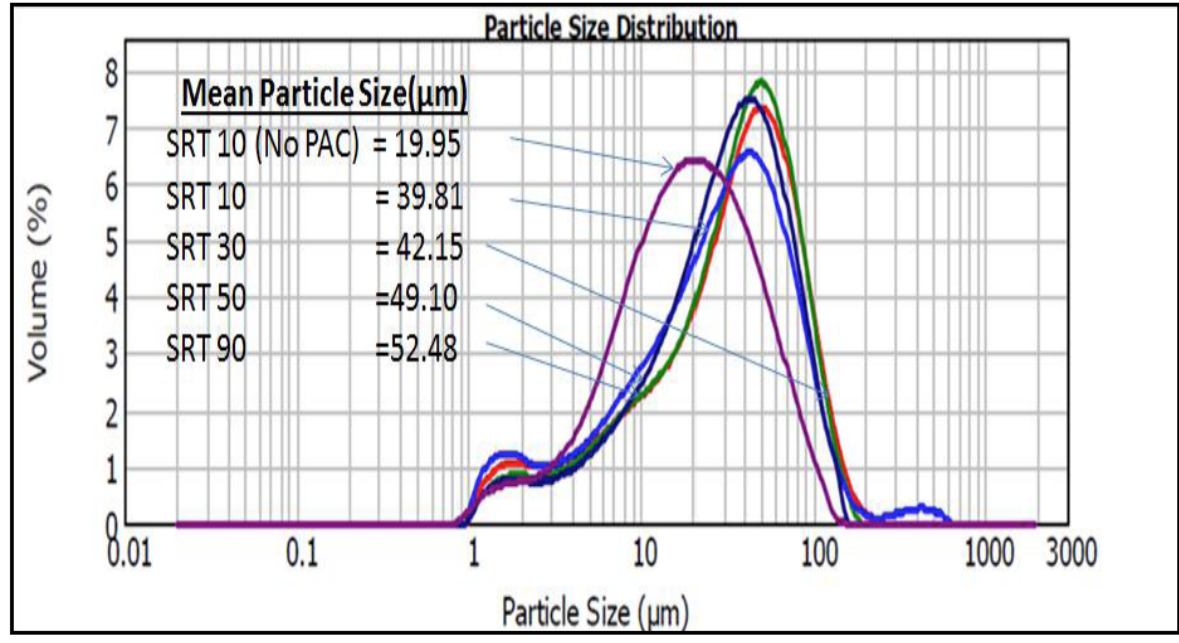

Figure 2: Particle size distribution of the biomass flocs in the AnMBRs at different SRTs. 


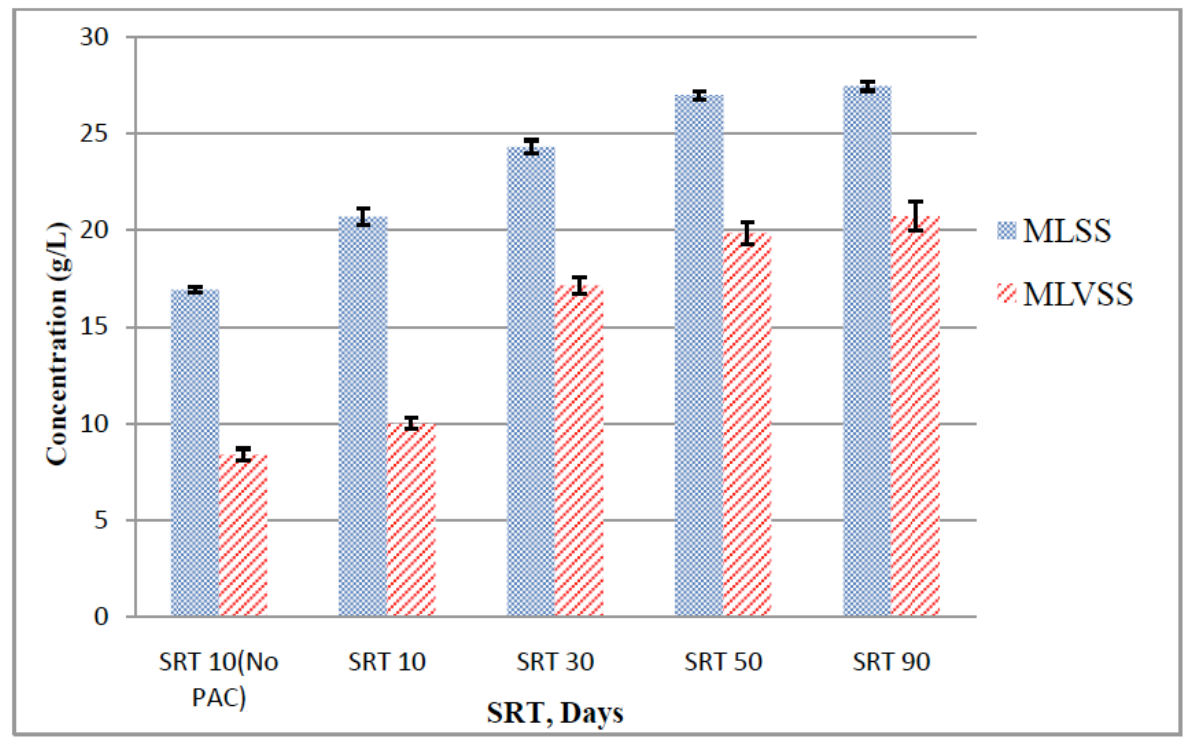

Figure 3: MLSS and MLVSS concentrations of the AnMBRs with different SRTs.

Table 5: Chemical Oxygen Demand (COD) Concentrations and Removal Rate of the AnMBRs.

\begin{tabular}{|c|c|c|c|}
\hline $\begin{array}{c}\text { Anaerobic Membrane } \\
\text { Bioreactors }\end{array}$ & POME influent (mg/L) & $\begin{array}{c}\text { Supernatant (mg/L) } \\
\text { Removal Rate }\end{array}$ & $\begin{array}{c}\text { Membrane effluent } \\
(\mathbf{m g} / \mathbf{L})\end{array}$ \\
\hline \hline AnMBR SRT 10 (No PAC) & $38000 \pm 100$ & $24000 \pm 48$ & $9800 \pm 51$ \\
\hline AnMBR SRT 10 & $38000 \pm 100$ & $20000 \pm 46$ & $9600 \pm 49$ \\
\hline AnMBR SRT 30 & $38000 \pm 100$ & $17000 \pm 50$ & $9500 \pm 48$ \\
\hline AnMBR SRT 50 & $38000 \pm 100$ & $16000 \pm 49$ & $9300 \pm 43$ \\
\hline AnMBR SRT 90 & $38000 \pm 100$ & $13000 \pm 47$ & $9100 \pm 52$ \\
\hline
\end{tabular}

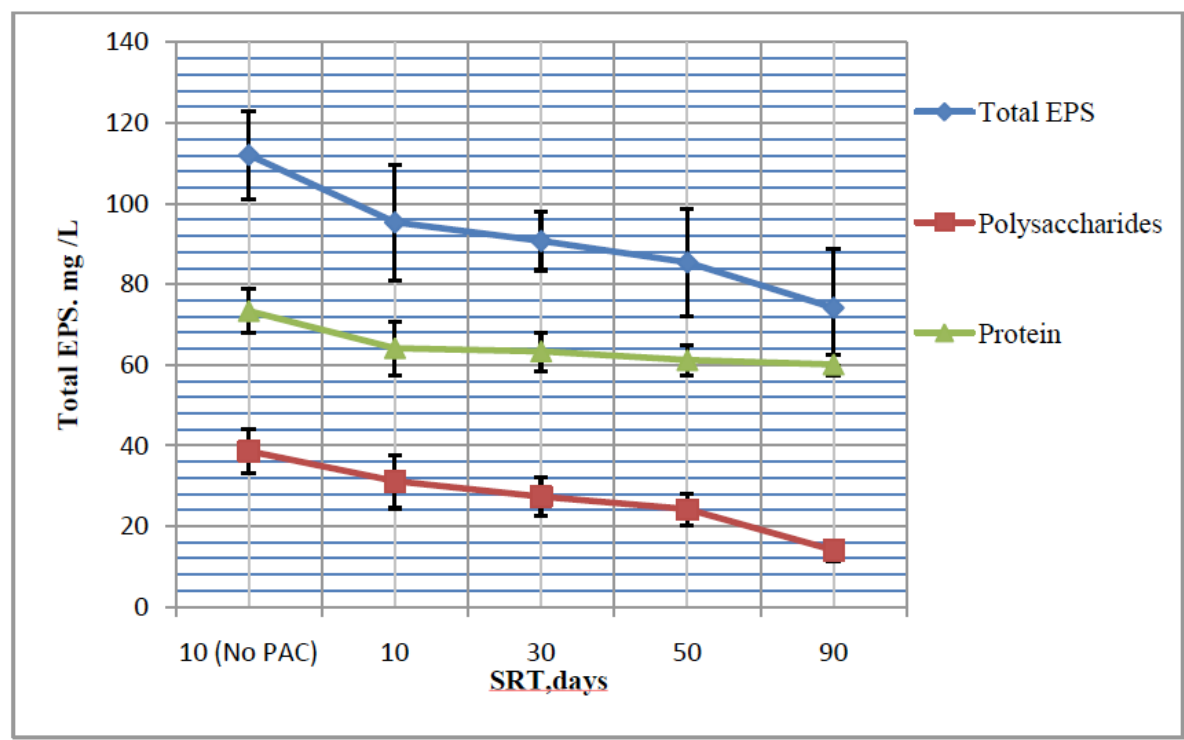

Figure 4: EPS concentration of the AnMBRs with different SRTs.

The performance of AnMBRs in membrane fouling control showed a direct proportional relationship with the fine pollutants such as total EPS, COD concentrations and particle sizes distribution of the flocs. The amount of fine particles was relatively high for the AnMBRs operated at the short SRT of 10 days, especially without the addition of PAC. This may be due to the fine pollutants tended to block the 
membrane pores more easily compared to larger particles in AnMBR which may lead to higher membrane fouling rate $[18,19]$. It shows that the membrane pores was more vulnerable to relatively smaller pollutants.

\subsection{Effects of Different SRTs on the Performances of AnMBRs in Wastewater Treatment}

The COD removal rates shown by the different AnMBRs with varied SRTs are given in Table 5. The initial COD influent of palm oil mill effluent (POME) was at the concentration of $38,000 \pm 1000 \mathrm{mg} / \mathrm{L}$. The performance of the AnMBRs with SRT 10 days (No PAC), SRT 10 days (with PAC), SRT 30 days (with PAC) , SRT 50 days (with PAC) and SRT 90 days (with $P A C$ ) in COD removal in terms of percentage was $74.2 \pm 0.1, \quad 74.7 \pm 0.1, \quad 75.0 \pm 0.1, \quad 75.5 \pm 0.1, \quad 76.1 \pm 0.1$ respectively.

The AnMBRs did not show significance variation in COD total removal efficiency under different operating SRTs but the concentration of the COD in the AnMBRs varied as per Table $\mathbf{5}$ and this explained the different membrane fouling control performance of the AnMBRs. As SRT increased from 10 days to 30 days, 30 days to 50 days and from 50 days to 90 days, the COD concentration in supernatant of the AnMBRs (added PAC) was reduced to $17,000 \mathrm{mg} / \mathrm{L}, 16,000 \mathrm{mg} / \mathrm{L}$ and $13,000 \mathrm{mg} / \mathrm{L}$ respectively. The maintenance cost of AnMBRs would be lower when the membrane fouling rate is slower. It shows that running the AnMBR added with PAC at the longer SRT is more economic and sustainable.

\subsection{Sludge Characteristics}

\subsubsection{Effects of Different SRTS on MLSS and MLVSS Concentrations in the AnMBRs}

Figure 3 shows the effects of addition of PAC on MLSS and MLVSS concentrations for the AnMBRs at the different SRTs. The AnMBR with the SRT of 10 days (added PAC) had relatively higher MLSS and MLVSS concentrations of $20.70 \mathrm{~g} / \mathrm{L}$ and $9.98 \mathrm{~g} / \mathrm{L}$ respectively when compared to the MLSS and MLVSS concentrations of the AnMBR with the SRT of 10 days (No PAC) which were $16.92 \mathrm{~g} / \mathrm{L}$ and $8.38 \mathrm{~g} / \mathrm{L}$, respectively.

This shows that the addition of PAC would increase the MLSS and MLVSS concentrations in AnMBRs. This is mainly due to the PAC has larger surface area per unit mass therefore it could enhance the microbial growth in the bioreactor $[15,20]$. Other AnMBRs added with PAC were also observed being able to enhance the biomass development with the best result was for the AnMBR at the SRT of 90 days.

When the SRT of the AnMBR (added PAC) was prolonged from 10 days to 30 days, the MLSS and MLVSS concentrations had increased to $24.32 \mathrm{~g} / \mathrm{L}$ and $17.14 \mathrm{~g} / \mathrm{L}$, respectively. The AnMBRs (added PAC) with SRTs 50 days and 90 days had quite similar MLSS and MLVSS concentrations as shown in Figure 3. As the sludge removal rate would reduce for the AnMBRs with the longer SRT, it means the amount of anaerobic bacteria retained in the bioreactor would be higher than that of the AnMBR with shorter SRT. The AnMBRs operated under the longer SRT would result in the higher accumulation of MLSS and MLVSS concentrations, however they did not cause an increase in membrane fouling. As observed in Figure 3, the MLSS and MLVSS concentrations were increased with prolonged SRT with the decreasing rate of membrane fouling in AnMBRs as shown in Figure 1. Higher concentrations of MLSS and MLVSS would improve the membrane fouling control performance of submerged AnMBRs was also observed [18]. This may be due to biomass concentration in the AnMBRs (added PAC) of prolonged SRT showed a better microbial growth rate as anaerobic bacteria had longer retention time in the bioreactor. Sufficient rate of growth and degradation period resulted in high pollutants removal rate as shown in Table 5 and Figure 2 and subsequently reducing the membrane fouling rate of the AnMBRs.

\subsubsection{Effects of Different SRTs on Food to Microorganisms (F/M) Ratio}

To understand better the effect of different SRTs on membrane fouling control of AnMBRs with and without the addition of PAC, it is also important to investigate the relationship of MLVSS concentration with food to microorganisms (F/M) ratio. F/M ratio represents the ratio of COD loading towards the MLVSS concentration. By changing the operating rate (SRT) of the AnMBRs, different F/M ratios were obtained. As shown in Figure 5, the AnMBR with the SRT of 10 days without PAC addition had the highest $\mathrm{F} / \mathrm{M}$ ratio of 7.75 as compared to the other AnMBRs. The AnMBRs with the shorter SRTs had a relatively high F/M ratio but the $\mathrm{F} / \mathrm{M}$ ratio decreased when SRT prolonged. F/M ratio is dependent to the MLVSS concentration in which the MLVSS concentration increased with PAC addition and prolonged SRT condition of the MBR system [19]. The 


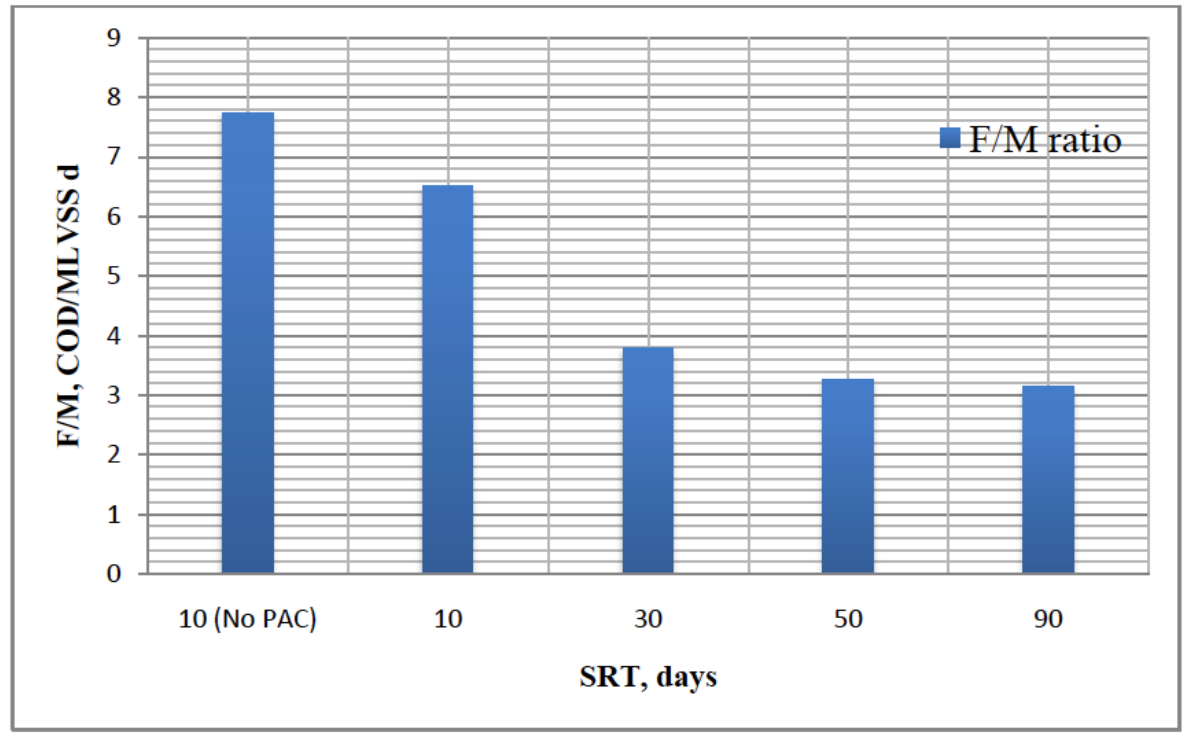

Figure 5: Food to microrganism (F/M) ratio of the AnMBRs at different SRTs.

AnMBRs with additional of PAC at the SRTs of 10, 30, and 50 and 90 days had $F / M$ ratio of $6.51,3.79,3.27$ and 3.14 , respectively.

\subsubsection{Effects of Different SRTs on Extracellular Polymeric Substances (EPS) Concentrations in AnMBRs}

Sludge retention time (SRT) of the AnMBR is one of the main operating parameters that would influence the formation of EPS. Yan et al. [21] found that EPS was an important factor affecting the membrane fouling in the AnMBRs. Figure $\mathbf{4}$ shows the highest concentrations of total EPS of $111.98 \mathrm{mg} / \mathrm{L}$ was with the AnMBR (without PAC) operated at the SRT of 10 days. However, the AnMBR added with PAC with 10 days of SRT had a relatively lower total EPS concentration of $95.29 \mathrm{mg} / \mathrm{L}$. This indicates that AnMBRs added with PAC would decrease the EPS concentration. It suggests that EPS production was related to microbial growth which indirectly proportion to the utilisation of the substrate in the AnMBRs [22].

Figure 4 also shows a decreasing trend in the total EPS concentration in the AnMBRs (added PAC) at longer SRTs. The total EPS concentration decreased from $95.29 \mathrm{mg} / \mathrm{L}$ to $90.69 \mathrm{mg} / \mathrm{L}$ when the SRT of the AnMBR (added PAC) increased from 10 days to 30 days. As the SRT was prolonged, the concentration of EPS in the AnMBRs would continue to decrease. The concentration of total EPS decreased from $90.69 \mathrm{mg} / \mathrm{L}$ to $85.4 \mathrm{mg} / \mathrm{L}$ when the SRT of the AnMBR was further prolonged from 30 to 50 days. Hence, the total EPS concentration would decline from $85.4 \mathrm{mg} / \mathrm{L}$ to 74.16 $\mathrm{mg} / \mathrm{L}$ when the SRT of the AnMBR was further increased from 50 to 90 days. EPS concentration was found to have proportional relationship to $\mathrm{F} / \mathrm{M}$ ratio, and have an inversely proportional relationship with MLSS and MLVSS concentrations. Thus, relatively higher F/M ratio would encourage the formation of EPS as shown in Figures $\mathbf{5}$ and $\mathbf{4}$. It indicates that higher MLSS and MLVSS concentrations and SRT of the AnMBRs would discourage the production of total EPS. This was mainly due to the AnMBRs (added PAC) with the higher SRT would promote microbial degradation of EPS.

\subsubsection{Effects of Different SRTs on Particle Size Distribution of Biomass Flocs in AnMBRs}

The effect of different operating SRTs of the AnMBRs on the mean particle size of the activated sludge flocs is shown in Figure 2. As shown in Figure 2, the particle size distribution of the AnMBR with the SRT of 10 days without the addition of PAC had the smallest mean particle size of $19.95 \mu \mathrm{m}$ among the others. As PAC was added to the AnMBR with SRT of 10 days, the mean particle size of the flocs had increased from $19.95 \mu \mathrm{m}$ to $39.81 \mu \mathrm{m}$. It had proven that PAC would help to increase the flocs size of the AnMBRs. When the AnMBR (added PAC) with the SRT of 10 days was increased to 30 days, the mean particle size distribution of the flocs increased from $39.81 \mu \mathrm{m}$ to $42.15 \mu \mathrm{m}$. The mean particle size of the floc was increased to $52.48 \mu \mathrm{m}$ for the AnMBR with the SRT of 90 days.

The longer the SRT for the AnMBRs (added with PAC), the bigger the floc size of their activated sludge. This is due to the transformation of PAC into biological 
activated carbon (BAC) sludge in the AnMBRs [20, 23]. PAC could act as a platform to promote the growth of biofilm population which is consists of non-motional acquainted and progression bacteria [24]. When the sludge retention time (SRT) is increased, the size of BAC tends to grow bigger as shown in Figure 2 which may be due to its relatively longer period of detainment.

BAC would equip itself with the processes which are consist of adsorption and biodegradation compared to single biological or adsorption process so this helps to enhance the overall membrane fouling control performance of the AnMBRs [12, 24]. When the SRT of the AnMBRs (added PAC) was prolonged, the overall performance of COD and total EPS removal efficiency in supernatants was improved as shown in Table $\mathbf{5}$ and Figure 4, respectively. Therefore, the membrane fouling control performance of the AnMBRs added with PAC was improved when SRT was prolonged.

\section{CONCLUSIONS}

The effects of different operating SRTs of the AnMBRs on membrane fouling with and without the addition of PAC were investigated by using five submerged AnMBRs with the different SRTs of 10, 30, 50 and 90 days. The removal efficiency of COD for the AnMBRs is higher with the addition of PAC and prolonged SRT (90 days). The MLSS and MLVSS concentrations in the AnMBRs would increase with the prolonged SRT. Therefore, F/M ratio would decrease with the prolonged SRT. This study suggested that the membrane fouling rate for the AnMBR would decrease if the $F / M$ ratio is decreased. Similar trend was observed for the AnMBRs (added PAC) which its EPS concentration would decrease by $33 \%$ by prolonging the SRT from 10 days to 90 days. This study also shows that, the particle size distribution of the AnMBR would increase with the addition of PAC. When the SRT was prolonged from 10 days to 90 days, the particle size distribution of the AnMBRs would increase. However, the increment in the particle size distribution was relatively small for the AnMBRs (added PAC) when the SRT was increased from 50 days to 90 days (about $6 \%$ ) as compared to increasing the SRT of 10 days to 90 days (about 62\%). This relatively minor increment suggested that the particle size distributions were enlarging towards maturity. Membrane fouling in the AnMBR was higher at a short SRT (10 days) with no PAC addition as compare to SRT (10 days) with PAC addition. It was found that membrane fouling rate was the lowest at the longer SRT of 90 days. This study could provide evidence that smaller colloidal particle and EPS concentration would contribute to the membrane fouling in the AnMBRs. This study also provides the fundamental information to relate the different SRTs and effect of PAC on microbial community and membrane fouling control in the submerged anaerobic membrane bioreactors.

\section{ACKNOWLEDGEMENT}

We would like to extend our gratitude to Ministry of Science, Technology and Innovation (MOSTI) for the fund with project No. 03-02-11SF0161. Sakti Suria (JB) Sdn. Bhd. is also acknowledged for their kindness to sponsor the membranes to carry out this study.

\section{REFERENCES}

[1] Ahmad AL, et al. Water Recycling from Palm Oil Mill Effluent (POME) Using Membrane Technology. Desalination 2003, 157: 87-95. http://dx.doi.org/10.1016/S0011-9164(03)00387-4

[2] Wong YS, Kadir MOAB, Teng TT. Biological kinetic evaluation of anaerobic stabilization pond treatment of palm oil mill effluent. Bioresource Technology 2009; 100: 49694975.

http://dx.doi.org/10.1016/j.biortech.2009.04.074

[3] Guest JS, Skerlos SJ, Barnard JL, et al. A new planning and design paradigm to achieve sustainable resource recovery from wastewater. Environ Sci Technol 2009, 43: 6126-6130. http://dx.doi.org/10.1021/es9010515

[4] Judd S. The MBR Book: Principles and Applications of Membrane Bioreactors for Water and Wastewater Treatment 2010. Butterworth-Heinemann, Oxford.

[5] Watanabe R, Qiao W, Norton M, Wakahara S, Li Y. Recent developments in municipal wastewater treatment using anaerobic membrane bioreactor: A Review. Journal of Water Sustainability 2014; 4(2): 101-122.

[6] Weiland P. Biogas production: current state and perspectives. Appl Microbiol Biotechnology 2010; 85: 849860.

http://dx.doi.org/10.1007/s00253-009-2246-7

[7] Bérubé PR, Hall ER, Sutton PM. Parameters governing permeate flux in an anaerobic membrane bioreactor treating low-strength municipal wastewaters: A literature review. Water Environment Research 2006; 78(8): 887-896. http://dx.doi.org/10.2175/106143005X72858

[8] Huang Z, Ong SL, Ng HY. Submerged anaerobic membrane bioreactor for low-strength wastewater treatment: Effect of HRT and SRT on treatment performance and membrane fouling. Water Research 2011; 45: 705-713. http://dx.doi.org/10.1016/j.watres.2010.08.035

[9] Masse A, Sperandio M, Cabassud C. Comparison of sludge characteristics and performance of a submerged membrane bioreactor and an activated sludge process at high solids retention time. Water Res 2006; 40(12): 2405-2415. http://dx.doi.org/10.1016/j.watres.2006.04.015

[10] Janeczko AK, Walters EB, Schuldt SJ, et al. Fate of malathion and a phosphonic acid in activated sludge with varying solids retention times. Water Research 2014; 57: 127-139. http://dx.doi.org/10.1016/j.watres.2014.03.031

[11] Lin HJ, Peng W, Zhang MJ, Chen JR, Hong HC, Zhang Y. A review on anaerobic membrane bioreactors: Applications, membrane fouling and future perspectives. Desalination 2013; 314: 169-188. 


\section{http://dx.doi.org/10.1016/j.desal.2013.01.019}

[12] $\quad \mathrm{Ng} \mathrm{CA}$, Darren S, Bashir JK, et al. Optimization of membrane bioreactors by the addition of powdered activated carbon. Bioresource Technology 2013; 138: 38-47. http://dx.doi.org/10.1016/j.biortech.2013.03.129

[13] Akram A, Stuckey DC. Flux and performance improvement in a submerged anaerobic membrane bioreactor (SAMBR) using powdered activated carbon (PAC). Process Biochemistry 2008; 43(1): 93-102. http://dx.doi.org/10.1016/j.procbio.2007.10.020

[14] Hu AY, Stuckey DC. Activated carbon addition to a submerged anaerobic membrane bioreactor: effect on performance, transmembrane pressure, and flux. J Environ Eng 2007; 133: 73-80. http://dx.doi.org/10.1061/(ASCE)0733-9372(2007)133:1(73)

[15] Ozgun H, Dereli RK, Ersahin ME, Kinaci C, Spanjers H, van Lier JB. A review of anaerobic membrane bioreactors for municipal wastewater treatment: Integration options, limitations and expectations. Separation and Purification Technology 2013; 118: 89-104. http://dx.doi.org/10.1016/j.seppur.2013.06.036

[16] Orshansky F, Narkis N. Characteristics of organics removal by PACT simultaneous adsorption and biodegradation. Water Resource 1997; 31: 391-398.

http://dx.doi.org/10.1016/s0043-1354(96)00227-8

[17] Masuko T, Metori K, Kizawa Y, Kusama T, Miyake M. Design and synthesis of a novel water-soluble NBDA receptor antagonist with a 1, 4, 7, 10-tetraazacyclododecane group. Chem Pharm Bull 2005; 53(4): 444-447. http://dx.doi.org/10.1248/cpb.53.444

[18] Wang XH, Qian JJ, Li XF, Chen K, Ren YP, Hua ZZ. Influences of sludge retention time on the performance of submerged membrane bioreactors with the addition of iron ion. Desalination 2012; 295: 24-29.

http://dx.doi.org/10.1016/j.desal.2012.04.002

[19] Zubair A, Cho J, Lim BR, Song KG, Ahn KH. Effects of sludge retention time on membrane fouling and microbial community structure in a membrane bioreactor. Journal of Membrane Science 2007; 287(2): 211-218. http://dx.doi.org/10.1016/j.memsci.2006.10.036

[20] Liu Y, Wang L, Cui H, Zhang J. Performance improvement of hybrid membrane bioreactor with PAC addition for water reuse. Water Science and Technology 2005; 52: 383-391.

[21] Yan XX, Bilad MR, Gerards R, Vriens L, Piasecka A, Vankelecom FJ. Comparison of MBR performance and membrane cleaning in a single-stage activated sludge system and a two-stage anaerobic/aerobic (A/A) system for treating synthetic molasses wastewater. Journal of Membrane Science 2012; 394-395: 49-56. http://dx.doi.org/10.1016/j.memsci.2011.12.014

[22] Laspidou CS, Rittman BE. Non-steady State Modelling of Extracellular Polymeric Subtances, Soluble Microbial Products, and Active and Inert Biomass. Water Research 2002; 36: 1983-1992. http://dx.doi.org/10.1016/S0043-1354(01)00414-6

[23] Kim JS, Lee $\mathrm{CH}$, Chun HD. Comparison of ultrafiltration characteristics between activated sludge and BAC sludge. Water Research 1998; 32: 3443-3451. http://dx.doi.org/10.1016/S0043-1354(98)00104-3

[24] Lin CK, Tsai TY, Liu JC, Chen MC. Enhanced biodegradation of petrochemical wastewater using ozonation and BAC advanced treatment system. Water Research 2000; 35: 699704.

http://dx.doi.org/10.1016/S0043-1354(00)00254-2 